\title{
The role of laparoscopy in the management of pediatric appendicitis: a survey of Polish pediatric surgeons
}

\author{
Andrzej Golebiewski, Piotr Czauderna \\ Department of Surgery and Urology for Children and Adolescents, Medical University of Gdansk, Gdansk, Poland
}

Videosurgery Miniinv 2015; 10 (1): 101-106

DOI: $10.5114 /$ wiitm.2014.47510

\begin{abstract}
Introduction: Despite the increase in use of laparoscopic appendectomy (LA) in recent years, until now no nationwide survey on this issue has been performed in Poland.

Aim: To determine current surgical practice patterns among Polish pediatric surgeons in the treatment of appendicitis in children.

Material and methods: The nationwide survey was conducted in the form of an internet questionnaire asking for information concerning treatment of children suspected of having acute appendicitis in the years 2007-2011. Twenty-seven major pediatric surgical departments in Poland were invited to participate in the study.

Results: The overall survey response rate was $70.37 \%$. Laparoscopic appendectomy was offered in all departments except one. Laparoscopy was used in 33\% of cases and was the standard procedure in 4 departments. In 1 center $100 \%$ of appendectomies were performed laparoscopically. The 3-port technique was used in all departments. Five centers offered transumbilical laparoscopic extracorporeal appendectomy and 2 centers single-port appendectomy. In LA the mesoappendix was mostly divided using bipolar or monopolar coagulation and the appendix was ligated using endoloops or was clipped. The mean hospitalization time was 3.31 days after laparoscopy and 5.47 days after open appendectomy.

Conclusions: Despite an apparent consensus on some aspects of pediatric appendicitis among Polish pediatric surgeons, significant inconsistency exists in the operative approach. The low rate of LA suggests that LA still remains far from being a standard. Personal experience and preference have a major influence on the choice of operative approach. It is recommended that national guidelines be set up, which could standardize the care for children and training of pediatric surgery residents.
\end{abstract}

Key words: appendectomy, survey, clinical guidelines, children.

\section{Introduction}

Although appendectomy remains the most common acute surgical procedure in children, considerable controversy still exists in terms of the surgical approach to acute appendicitis in the pediatric population. Despite the general consensus among pediatric surgeons that the removal of the appendix is the most effective way to treat the inflammation, a uniform policy concerning this pathology is still lacking. In recent years the availability of novel diagnostic methods and development of minimally invasive surgery have led to a change of pre-operative and operational approach. Since the use of laparoscopy in Poland increased in recent years, we decided to analyze nation-wide data concerning appendectomy over a recent timeline, in order to assess changes in prevalence of the laparoscopic approach and its impact on the results. 
Many factors influence the management of appendicitis in children, and even within a single institution inconsistency between surgeons exists. Despite new procedural techniques having emerged, no nationwide survey exists regarding the approach to pediatric appendectomy in Poland. Similar surveys in children have already been conducted in the USA, Holland, Germany and Israel [1-5]. In Poland, national guidelines concerning diagnosis and treatment of acute appendicitis are still lacking, but some hospitals have adopted local guidelines. The improvement of the diagnosis and treatment of this pathology in children in Poland requires firstly a thorough understanding of the current management practices.

\section{Aim}

The aim of this study was to examine the current practice patterns among Polish pediatric surgeons in the treatment of appendicitis and to determine whether a consensus exists in the surgical management of this pathology.

\section{Material and methods}

A national survey was conducted using a questionnaire sent via the Internet, asking for detailed information concerning diagnosis and treatment of children suspected of having acute appendicitis in the years 2007-2011. Twenty-seven pediatric surgical departments in Poland (16 university and 11 regional non-teaching) were asked to answer questions concerning the size of the department, total number of operations, number of appendectomies, use of laparoscopy, applied procedural techniques, and duration of hospitalization.

\section{Statistical analysis}

Statistical analyses were carried out using "Statistica" software. Values of $p<0.05$ was considered significant. The two-sample Student's t-test or the Mann-Whitney $U$-test was used for continuous variables, depending on data normality.

\section{Results}

The overall survey response rate was $70.37 \%$. A total of 12 university teaching departments (75.00\%) and 7 regional departments (63.63\%) responded to our survey. Characteristics of the departments in the year 2011 are presented in Table I. All departments except one performed appendectomy as an emergency procedure. The overall number of beds ranged from 25 to 52 (mean 37), and the number of operations ranged from 901 to 3136 (mean 1680) per year. University departments were slightly bigger than regional ones (38 and 34 beds, respectively) and performed annually significantly more operations (1858 and 1235 , respectively, $p=0.041$ ). During the study period appendectomy accounted for $5.42 \%$ of all procedures performed in the surveyed hospitals. There was a statistically significantly higher rate of appendectomies $(p=0.026)$ in regional departments $(7.82 \%)$ than in university departments (4.38\%).

Laparoscopic equipment has been available since 2007 in 17 departments, in 12 of them for a period exceeding 7 years. One unit only acquired laparoscopic equipment in 2012. During the study period in the hospitals where laparoscopy was available, $5.54 \%$ of the operations were done using the minimally invasive method. Laparoscopic procedures accounted for a greater proportion of operations in university departments compared to regional ones (respectively $6.01 \%$ and $3.98 \%, p=0.033$ ). During our study period 3 hospitals received laparoscopic equipment (2 in 2007 and 1 in 2010), and the percentage of laparoscopic procedures showed an upward trend throughout the study period (Table II). In 2011, all hospitals except one (94\%) offered laparoscopic appendectomy (LA). During the study period

Table I. Characteristics of departments participating in the survey

\begin{tabular}{|lccc|}
\hline Parameter & $\begin{array}{c}\text { Teaching hospitals } \\
(n=12)\end{array}$ & $\begin{array}{c}\text { Non-teaching } \\
\text { hospitals }(n=7)\end{array}$ & Value of $p$ \\
\hline Number of beds, mean & 38 & 34 & $>05$ \\
\hline Number of operations, mean per year & 1858 & 1235 & 0.041 \\
\hline Percentage of appendectomies & 4.38 & 7.82 & 0.026 \\
\hline Percentage of laparoscopic procedures & 6.01 & 3.98 & 0.033 \\
\hline
\end{tabular}


Table II. Rate of laparoscopic procedures

\begin{tabular}{|lccccc|}
\hline Parameter & 2007 & 2008 & 2009 & 2010 & 2011 \\
\hline Number of departments equipped with laparoscopy & 17 & 17 & 17 & 18 & 18 \\
\hline Percentage of laparoscopic procedures & 4.98 & 4.91 & 5.62 & 5.74 & 6.44 \\
\hline
\end{tabular}

laparoscopy was used in most of the hospitals, and the rate of laparoscopy in the last year was 33\%. During the study period the rate of appendectomies showed a slight increase (Figure 1). Only 4 centers (3 teaching and 1 non-teaching) favored this surgical approach and performed more than $50 \%$ of appendectomies laparoscopically. Laparoscopic appendectomy was the standard procedure (100\% of cases) in 1 teaching department. A low rate of laparoscopy ( $<25 \%$ ) was found in $50 \%$ of teaching and $71 \%$ of non-teaching hospitals. None of the non-teaching hospitals treated laparoscopically over $75 \%$ of appendectomies (Figure 2). The median rates of laparoscopy use in 2011 in teaching and non-teaching hospitals were $35.2 \%$ and $25.2 \%$, respectively. It is interesting that in the years 2008 and 2009 regional hospitals performed more laparoscopic procedures compared to university ones. This trend was reversed in 2010 and 2011. The changing trends during the study period are presented in Figure 3.

The 3-port technique was preferred in all departments performing laparoscopic appendectomy. Transumbilical laparoscopic extracorporeal appendectomy was performed in 5 departments and in 1 accounted for more than $50 \%$ of LA. In 4 others it was performed occasionally. The appendix was extracted

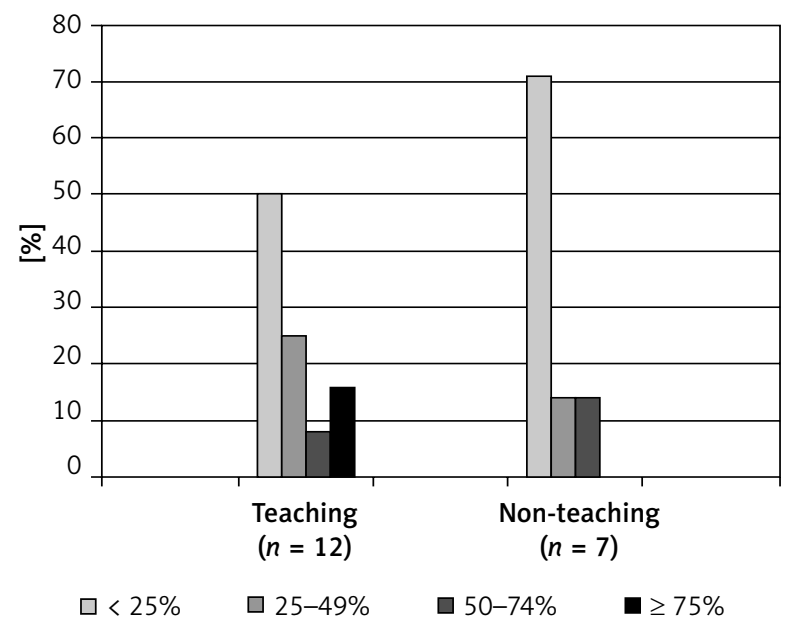

Figure 2. Laparoscopic appendectomy in teaching and non-teaching hospitals

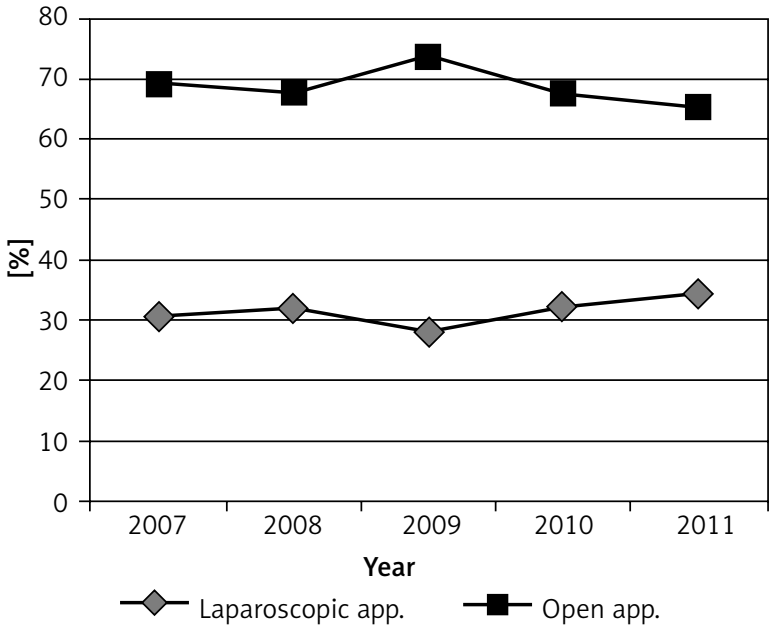

Figure 1. Rate of open and laparoscopic appendectomy

in the right iliac fossa in 3 departments and through the umbilicus in 2 departments.

Two centers offered single-port appendectomy, but it was performed only in individual cases.

During laparoscopic appendectomy the mesoappendix was divided by means of monopolar cautery (60\% of departments), bipolar coagulation (35\%), harmonic scalpel (15\%) or bipolar sealing device (10\%).

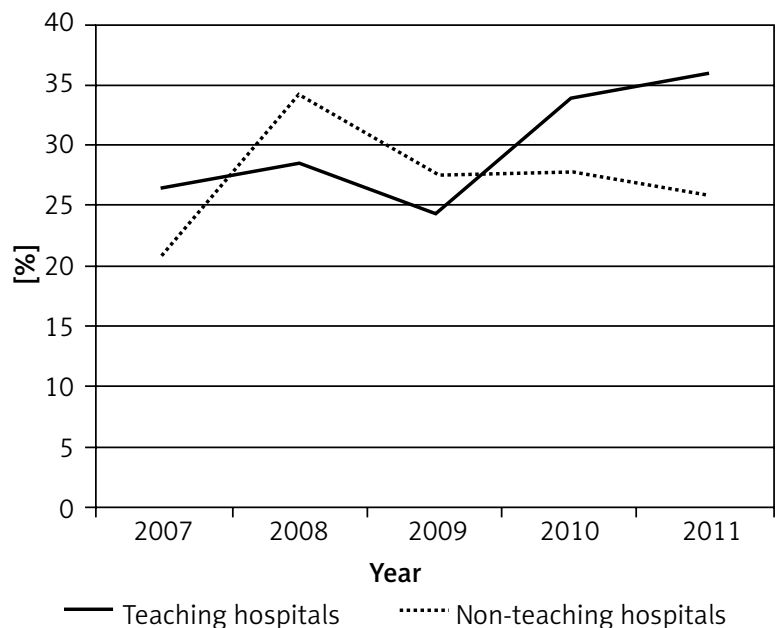

Figure 3. Rate of laparoscopic appendectomy in the years 2007-2011 
In laparoscopic appendectomy the appendix was mostly ligated using 1 or 2 endoloops, and in 2 centers it was clipped. In an extracorporeal technique, the mesoappendix and appendix were always ligated. Neither in intracorporeal nor in extracorporeal appendectomy was the stump ever invaginated by means of a purse-string or ' $Z$ ' suture.

The conversion rate was $0.36 \%$. More than $50 \%$ of departments did not report conversions. In 3 centers the conversion rate was over $10 \%$.

The median hospital stay for patients undergoing laparotomy was 5.47 days. A shorter hospitalization of 3.31 days was associated with laparoscopy $(p=0.03)$.

\section{Discussion}

Open appendectomy has been the "gold standard" of treatment for acute appendicitis for more than 100 years. Despite the first reported video-assisted LA in an adult patient by Semm in 1983 [6], the acceptance of LA by surgeons was quite slow compared to laparoscopic cholecystectomy. In the early 2000 s the rate of LA was around $10 \%$ globally. However, in the last decade a universal trend toward an increased use of LA has been observed $[2,7,8]$.

Our analysis showed that also in Poland pediatric surgeons are introducing LA as the method of choice for the treatment of acute appendicitis. More surgeons are familiar with the concept of minimally invasive surgery and perform LA more frequently. On the other hand, some experts still consider open appendectomy as a preferred approach for patients with acute appendicitis, especially in complicated cases.

Laparoscopic appendectomy was performed in all hospitals having suitable equipment, and the rate of LA in 2011 varied from 5\% to $100 \%$ with a mean of $33 \%$. Only a few departments favored this surgical approach (4 hospitals did LA in more than $50 \%$ of cases), and in one department all appendectomies were performed laparoscopically. In the study period the percentage of LA varied from 29 to $33 \%$. It is comparable with data from the USA from early 2000 , where data from 30 children's hospitals showed that $31 \%$ of pediatric appendectomies were performed laparoscopically [9]. In USA from 1998 to 2007 the LA rate among pediatric patients increased from $22.2 \%$ to $70 \%$ [6], reaching $90.8 \%$ in 2010 [2]. In Europe this increase was not so clear, with around $11 \%$ to $50 \%$ of pediatric appendectomies performed laparoscop- ically $[3,5]$. In our analysis, it was found that LA can be performed safely and effectively in many settings of appendicitis and was associated with a shorter hospital stay. We intend to monitor any changes in surgical approach in a following study. A low rate of laparoscopy (<25\%) was found in $50 \%$ of university hospitals and $71 \%$ of non-teaching hospitals. The low rate of laparoscopy in some teaching hospitals seems surprising, bearing in mind the fact that laparoscopy has confirmed benefits in the treatment of appendicitis [10, 11]. Laparoscopic appendectomy is proven to be suitable for children, and no longer considered a contraindication in complicated appendicitis [12, 13].

Length of hospitalization was found to be shorter after laparoscopy (3.31 days) compared to the open approach (5.47 days), which is consistent with multiple studies [14-16]. The laparoscopic approach allows for an earlier return to normal activity and better quality of life scores at 2 weeks after appendectomy in patients who have undergone LA compared to OA [17].

Furthermore, LA reduces the risk of postoperative small bowel obstructions, minimizes the wound infection rate, and does not increase the risk of postoperative abscess rate [18-20].

Laparoscopy is also favored in young patients for cosmesis [21].

In addition to the many benefits to the patient associated with the laparoscopic approach presented in the randomized studies and meta-analyses $[10,11,17]$, one should also take into account the training aspect of LA. For surgical residents the LA is often the first procedure performed laparoscopically. It allows them to improve the technique for placing trocars and using new tools, as well as improving coordination when working in the operating field imaged on the flat screen [22]. Many of the steps performed during laparoscopic appendectomy are mandatory skills for more advanced procedures. While laparoscopic appendectomy is regarded by many surgeons as the perfect teaching tool for introducing surgical residents to advanced laparoscopic procedures, some surgeons still refuse to use it due to elevated costs. However, in teaching hospitals financial matters should not be the most important consideration. As shown by Lintula et al. [23], LA was slightly more expensive, but permitted an earlier return to normal daily activities compared to open appendectomy. Although laparoscopy seems to 
be slowly making its way into the surgical armamentarium, the low rate of laparoscopic appendectomies in teaching hospitals raises the issue of appropriate resident training.

The low prevalence of LA in Poland seems to be caused by many factors. One of them may be the lack of access to laparoscopic equipment during oncall periods, when the majority of appendectomies are performed. Another problem is the higher cost of disposable laparoscopic equipment: harmonic knife, endoloops, etc. Laparoscopic appendectomy costs may be reduced by omission of the use of expensive disposable equipment (harmonic knife, sealing devices, etc). Bipolar or even monopolar coagulation seems sufficient to ligate the mesoappendix $[4,24]$.

Use of the laparoscopically assisted technique, which does not require ready-made endoscopic ligatures, and in which the appendix is provided with a conventional ligature after emerging outside the abdominal cavity, may lead to even further reductions of costs $[25,26]$.

The one-trocar appendectomy combines the advantages of laparoscopic surgery with those of open surgery. The benefits of this technique include cosmesis, shorter operation time and reduced costs compared with laparoscopic appendectomy. However, mobilization and extraction of the appendix are not always possible with one instrument. A great limitation of the procedure is a subserous or strongly adherent appendix. However, in our study the use of one-port technique was feasible in $48 \%$ of cases [27]. Extracorporeal appendectomy has also been associated with low costs and a shorter learning curve $[25,26]$.

Another observed trend in this study was a difference in operative practice between surgeons from teaching and non-teaching hospitals. In general, the LA was employed more often in university hospitals.

It is possible that the lack of availability of laparoscopic equipment during emergency duties may have contributed to the low incidence of laparoscopic appendectomy in the regional hospitals. The main reason for the low rate of LA seems to be the individual preferences of surgeons on duty, lack of training in laparoscopic techniques, longer operation time, and uncertainty regarding better outcomes of minimally invasive treatments. According to a U.S. study, $59 \%$ of pediatric surgeons admitted being guided in their practice by their individual preferences [13].
Certainly, the difference in perceived benefits of the laparoscopic approach is an important factor in determining the choice of method [28].

The data suggest that a combination of operative philosophy, surgical skills and equipment availability account for the marked differences in laparoscopic utilization in the institutions in Poland as well globally.

The presented data demonstrated that the laparoscopic approach in Poland is far from being a standard in clinical practice, and the open approach still remains favored by Polish pediatric surgeons.

We believe that the study, with its sample size (response rate $>70 \%$ ), presents an accurate depiction of actual practices of pediatric surgeons from most major Polish centers. The results of this study document the inconsistency among institutions in the management of pediatric appendicitis. The collected data, which seem reliable, can be used to develop guidelines to improve clinical practice and optimize utilization of resources.

\section{Conclusions}

Principles of treatment of acute appendicitis in children in Poland are far from standardized, especially in the area of surgical treatment. Inconsistency exists in the type of surgical approach. Our study also draws attention to the low percentage of laparoscopic procedures performed, despite the availability of appropriate equipment in most hospitals. The low rate of LA despite equipment availability suggests that personal experience and preference have a major influence on the choice of operative approach. It seems therefore important to put more emphasis on the training of pediatric surgery residents in the field of laparoscopic surgery.

We propose to use the information gathered to create national guidelines for the management of acute appendicitis in children. Appropriate standards of treatment can improve the quality of care and reduce costs.

\section{Acknowledgments}

The authors thank all the responding surgical departments for their cooperation. We would like to thank the following people for their contribution, without whose time and effort this work would not have been completed: Dominika Smyczek ${ }^{1}$, Grzegorz Kudela ${ }^{1}$, Tomasz Janowicz ${ }^{2}$, Wojciech Choiński², Krzysztof Dymek $^{3}$, Irena Daniluk-Matraś ${ }^{3}$, Tomasz Grzechnik ${ }^{4}$, Martin Inman ${ }^{4}$, Adam Wilczyński ${ }^{5}$, Jan Zagierski ${ }^{5}$, Krzysztof Królak ${ }^{6}$, Piotr Stępieńn, Sławomir Osman, Przemysław Wolak7, Arkadiusz Jesionowski, 
Roman Sławek ${ }^{7}$, Anna Małgorzata Piaseczna-Piotrowska ${ }^{8}$, Patrycja Sosnowska ${ }^{9}$, Przemysław Mańkowski ${ }^{9}$, Andrzej Jankowski ${ }^{9}$, Elżbieta Gawrych ${ }^{10}$, Andrzej Kowal ${ }^{11}$, Weronika Jaroń ${ }^{12}$, Adam Kowalski ${ }^{12}$ Karolina Standio-Pomorska ${ }^{13}$, Anna Wasztan ${ }^{13}$, Sylwester Gerus ${ }^{14}$, Dariusz Patkowski ${ }^{14}$, Justyna Sitnik ${ }^{14}$, Aleksandra Zimmer ${ }^{14}$, Konrad Pieszko ${ }^{14}$, Piotr Kaczmarek ${ }^{14}$, Maciej Bagłaj ${ }^{14}$, Michał Pasierbek ${ }^{15}$, Jan Nowak ${ }^{16}$, Marcin Ulasiński ${ }^{17}$, Paweł Pękała ${ }^{17}$, Elżbieta Szymańs$\mathrm{ka}^{18}$ ('Department of Pediatric Surgery and Urology, Medical University of Silesia, Katowice; ${ }^{2}$ Department of Pediatric Surgery, Regional Children's Specialist Hospital, Olsztyn, University of Warmia and Mazury, Olsztyn; ${ }^{3}$ Department of Pediatric Surgery, Nicolaus Copernicus University, Bydgoszcz; ${ }^{4}$ Department of Pediatric Surgery, Traumatology and Urology, Regional Hospital, Gorzow Wielkopolski; ${ }^{5}$ Department of Pediatric Surgery and Traumatology, Regional Hospital, Grudziądz; ' ${ }^{6}$ epartment of Pediatric Surgery, Regional Mother's and Child's Hospital, Kalisz; ${ }^{7}$ Department of Pediatric Surgery, Urology and Traumatology, Regional Hospital, Kielce; ${ }^{8}$ Department of Pediatric Surgery and Urology, Polish Mother's Health Institute, Lodz; ' ${ }^{\circ}$ epartment of Pediatric Surgery, Traumatology and Urology, Poznan University of Medical Sciences, Poznan; ${ }^{10}$ Department of Pediatric and Oncological Surgery, Pomeranian Medical University, Szczecin; ${ }^{11}$ Department of Pediatric Surgery, Institute of Mother and Child, Warsaw; ${ }^{12}$ Department of Pediatric Surgery and Organ Transplantation, Children's Memorial Health Institute, Warsaw ${ }^{13}$ Department of Pediatric Surgery, Medical University of Warsaw, Warsaw; ${ }^{14}$ Department of Pediatric Surgery and Urology, Medica University, Wrocław; ${ }^{15}$ Department of Surgery of Congenital Defects in Children and Traumatology, Silesian Medical University, Zabrze; ${ }^{16}$ Department of Pediatric Surgery, Neonatal Surgery, Traumatology and Urology, Zielona Gora; ${ }^{17}$ Department of Pediatric Surgery, Wejherowo; ${ }^{18}$ Department of Pediatric Surgery, Koszalin).

\section{Conflict of interest}

\section{The authors declare no conflict of interest.}

\section{References}

1. Muehlstedt SG, Pham TQ, Schmeling DJ. The management of pediatric appendicitis: a survey of North American pediatric surgeons. J Pediatr Surg 2004; 39: 875-9.

2. Gasior AC, St Peter SD, Knott EM, et al. National trends in approach and outcomes with appendicitis in children. J Pediatr Surg 2012; 47: 2264-7.

3. Tan EC, Severijnen RS, Rosman C, et al. Diagnosis and treatment of acute appendicitis in children: a survey among Dutch surgeons and comparison with evidence-based practice. World J Surg 2006; 30: 512-8.

4. Dingemann J, Metzelder ML, Szavy PO. Current status of laparoscopic appendectomy in children: a nation wide survey in Germany. Eur J Pediatr Surg 2013; 23: 226-33.

5. Mogilner JG, Slijper N, Kandelis E, et al. The management of pediatric appendicitis: an opinion survey of Israeli pediatric surgeons. Harefuah 20007; 146: 414-9.

6. Semm K. Endoscopic appendectomy. Endoscopy 1983; 15: 59-64.

7. Lee SL, Yaghoubian A, Kaji A. Laparoscopic vs open appendectomy in children. Outcomes comparison based on age, sex, and perforation status. Arch Surg 2011; 146: 1118-21.

8. Gagné J, Billard, M, Gagnon R, et al. Province-wide population survey of acute appendicitis in Canada. New twists to an old disease. Surg Endosc 2007; 21: 1383-7.

9. Newman K, Ponsky T, Kittle K, et al. Appendicitis 2000: variability in practice, outcomes, and resource utilization at thirty pediatric hospitals. J Pediatr Surg 2003; 38: 372-9.
10. Aziz O, Athanasiou T, Tekkis P, et al. Laparoscopic versus open appendectomy in children: a meta-analysis. Ann Surg 2006; 243: 17-27.

11. Li X, Zhang J, Sang L, et al. Laparoscopic versus conventional appendectomy - a meta-analysis of randomized controlled trials. BMC Gastroenterol 2010; 10: 129-35.

12. Tsai CC, Lee SY, Huang FC. Laparoscopic versus open appendectomy in the management of all stages of acute appendicitis in children: a retrospective study. Pediatr Neonatol 2012; 53: 289-94.

13. Chen C, Botelho C, Cooper A, et al. Current practice patterns in the treatment of perforated appendicitis in children. J Am Coll Surg 2003; 196: 212-21.

14. Esposito C, Borzi P, Valla JS, et al. Laparoscopic versus open appendectomy in children: a retrospective comparative study of 2,332 cases. World J Surg 2007; 31: 750-5.

15. Yong JL, Law WL, Lo CY, et al. A comparative study of routine laparoscopic versus open appendectomy. JSLS 2006; 10: 188-92.

16. Lin HF, Wu JM, Tseng LM, et al. Laparoscopic versus open appendectomy for perforated appendicitis. J Gastrointest Surg 2006; 10: 906-10.

17. Katkhouda N, Mason RJ, Towfigh S, et al. Laparoscopic versus open appendectomy: a prospective randomized double-blind study. Ann Surg 2005; 242: 439-48.

18. Nataraja RM, Teague WJ, Galea J, et al. Comparison of intraabdominal abscess formation after laparoscopic and open appendicectomies in children. J Pediatr Surg 2012; 47: 317-21.

19. Tsao KJ, St Peter SD, Valusek PA, et al. Adhesive small bowel obstruction after appendectomy in children: comparison between the laparoscopic and open approach. J Pediatr Surg 2007; 42: 939-42.

20. Khan MN, Fayyad T, Cecil TD, et al. Laparoscopic versus open appendectomy: the risk of postoperative infectious complications. JSLS 2007; 11: 363-7.

21. Lee CH, Lin YL. Laparoscopic appendectomy in children: another opinion. Int Surg 2003; 88: 92-4.

22. Carrasco-Prats M, Caledo VS, Lujan-Mompean JA, et al. Role of appendectomy in training for laparoscopic surgery. Surg Endosc 2003; 17: 111-4.

23. Lintula H, Kokki H, Vanamo K, et al. The costs and effects of laparoscopic appendectomy in children. Arch Pediatr Adolesc Med 2004; 158: 34-7.

24. Davila D, Russek K, Mranklin ME Jr. Laparoscopic appendectomy: vascular control of appendicular artery using monopolar cauterization versus clips. J Laparoendosc Adv Surg Tech A 2012; 22: 165-7.

25. Visnjic S. Transumbilical laparoscopically assisted appendectomy in children. High-tech low-budget surgery. Surg Endosc 2008; 22: 1667-71.

26. Adhikary S, Tyagi S, Sapkota G, et al. Port exteriorization appendectomy: is it the future? Nepal Med Coll J 2008; 10: 30-4.

27. Gołębiewski A, Losin M, Murawski M, et al. One, two, three port appendectomy - a rational approach. Videosurgery Miniinv 2013; 8: 226-31.

28. McCartan DP, Fleming FJ, Hill AD. Patient and surgeon factors are associated with the use of laparoscopy in appendicitis. Colorectal Dis 2011; 14: 243-9.

Received: 23.09.2014, accepted: 26.10.2014. 